\title{
Calcium, magnesium and potassium intake and mortality in women with heart failure: the Women's Health Initiative
}

\author{
Emily B. Levitan ${ }^{1 *}$, James M. Shikany ${ }^{1}$, Ali Ahmed ${ }^{1,2}$, Linda G. Snetselaar ${ }^{3}$, Lisa W. Martin ${ }^{4}$, \\ J. David Curb ${ }^{5}+$ and Cora E. Lewis ${ }^{1}$ \\ ${ }^{1}$ University of Alabama at Birmingham, Department of Epidemiology, 1530 3rd Avenue South, RPHB 230K, Birmingham, \\ AL 35924-0022, USA \\ ${ }^{2}$ Birmingham Veterans Affairs Medical Center, 700 19th Street South, Birmingham, AL 35233, USA \\ ${ }^{3}$ University of Iowa, 801 Newton Road, Iowa City, IA 52246, USA \\ ${ }^{4}$ George Washington University, 2121 I Street Northwest, Washington, DC 20052, USA \\ ${ }^{5}$ University of Hawaii at Manoa, 2500 Campus Road, Honolulu, HI 96822, USA \\ (Submitted 13 April 2012 - Final revision received 3 August 2012 - Accepted 10 September 2012 - First published online 19 November 2012)
}

\begin{abstract}
Although diet is thought to affect the natural history of heart failure (HF), nutrient intake in HF patients has not been well studied. Based on prior research linking high intake of $\mathrm{Ca}, \mathrm{Mg}$ and $\mathrm{K}$ to improved cardiovascular health, we hypothesised that these nutrients would be inversely associated with mortality in people with HF. Of the 161808 participants in the Women's Health Initiative (WHI), we studied 3340 who experienced a HF hospitalisation. These participants were followed for post-hospitalisation all-cause mortality. Intake was assessed using questionnaires on food and supplement intake. Hazard ratios (HR) and 95\% CI were calculated using Cox proportional hazards models adjusted for demographics, physical function, co-morbidities and dietary covariates. Over a median of 4.6 years of follow-up, 1433 (42.9\%) of the women died. HR across quartiles of dietary Ca intake were 1.00 (referent), 0.86 (95\% CI 0.73, 1.00), 0.88 (95\% CI 0.75, 1.04) and 0.92 (95\% CI $0 \cdot 76,1 \cdot 11)$ ( $P$ for trend=0.63). Corresponding HR were 1.00 (referent), 0.86 (95\% CI $0 \cdot 71,1 \cdot 04), 0 \cdot 88$ (95\% CI $0.69,1 \cdot 11)$ and $0 \cdot 84$ (95\% CI $0.63,1.12$ ) ( $P$ for trend=0.29), across quartiles of dietary Mg intake, and 1.00 (referent), 1.20 (95\% CI $1.01,1.43), 1 \cdot 06$ (95\% CI $0 \cdot 86,1.32)$ and $1.16(95 \%$ CI $0.90,1.51)$ ( $P$ for trend $=0.35)$, across quartiles of dietary K intake. Results were similar when total (dietary plus supplemental) nutrient intakes were examined. In summary, among WHI participants with incident HF hospitalisation, intakes of Ca, Mg and $\mathrm{K}$ were not significantly associated with subsequent mortality.
\end{abstract}

Key words: Heart failure: Mortality: Calcium: Magnesium: Potassium

Although diet is thought to affect the natural history of heart failure $(\mathrm{HF})^{(1)}$, only a few studies have sought to determine the effect of nutritional intake in patients with $\mathrm{HF}^{(2-7)}$. Many of these studies were small and examined the effect of dietary supplements, rather than nutrient intake from food. The intake of $\mathrm{Ca}, \mathrm{Mg}$ and $\mathrm{K}$ could influence the course of HF through effects on blood pressure, inflammation, endothelial function and other pathways ${ }^{(8-16)}$. In one small study, high-dose supplementation with multiple micronutrients, including $\mathrm{Ca}$ and $\mathrm{Mg}$, improved left ventricular function and quality of life among HF patients with reduced ejection fraction ${ }^{(6)}$. However, the effect of $\mathrm{Ca}, \mathrm{Mg}$ and $\mathrm{K}$ intake on survival in patients with $\mathrm{HF}$ is not known. We therefore examined the associations of $\mathrm{Ca}, \mathrm{Mg}$ and $\mathrm{K}$ intake from foods, as well as total intake from diet and supplements, with all-cause mortality among Women's Health Initiative (WHI) participants who had a HF hospitalisation. We hypothesised that higher intake of $\mathrm{Ca}$, $\mathrm{Mg}$ and $\mathrm{K}$ would be associated with lower rates of all-cause mortality in women with HF.

\section{Methods}

\section{Study population}

The WHI has been previously described in depth ${ }^{(17,18)}$ Briefly, the WHI consisted of a clinical trial component with 68132 post-menopausal women aged 50-79 years at the study entry and an observational study component with

Abbreviations: DM, dietary modification; HF, heart failure; WHI, Women's Health Initiative.

*Corresponding author: E. B. Levitan, fax +1205934 8665, email elevitan@uab.edu

† Deceased. 
93676 post-menopausal women aged 50-79 years at the study entry, recruited between 1993 and 1998 through forty clinical centres. The WHI clinical trial included trials of hormone therapy, dietary modification (DM) and Ca plus vitamin D. The clinical trial and observational study were closed in 2004-05, and participants were invited to continue in the WHI extension study, which started in 2005. For the present analysis, we focused on the 4043 participants who had an adjudicated hospitalisation for HF between study entry and 2005. HF hospitalisations were locally adjudicated with central adjudication for quality control and were defined as hospitalisations with a final diagnosis of HF accompanied by medical treatment for $\mathrm{HF}$, including diuretics, digitalis, vasodilators or angiotensin-converting enzyme inhibitors. Supporting evidence of $\mathrm{HF}$ from imaging was also noted. We excluded twenty-nine participants who did not survive at least $1 \mathrm{~d}$ past HF hospitalisation, 480 participants missing information on $\mathrm{Ca}, \mathrm{Mg}, \mathrm{K}$ or covariates and 194 participants with implausible energy intake $(<2510$ or $>20920 \mathrm{~kJ} / \mathrm{d})$ producing a final sample size of 3340 women. The present study was conducted according to the guidelines laid down in the Declaration of Helsinki, and all procedures involving human subjects were approved by the institutional review boards at all the participating centres. Written informed consent was obtained from all the participants.

\section{Nutrient intake}

A modified block $\mathrm{FFQ}^{(19)}$ was administered during a screening visit for all the participants and additionally at year 1 for all participants in the DM trial, yearly thereafter for a proportion of the DM participants and at year 3 for the observational study participants. The most recent diet assessment prior to HF hospitalisation was selected for each participant. The FFQ contained 122 questions about the frequency of consumption of foods and beverages over the previous 3 months, nineteen adjustment items and four summary questions $^{(19)}$. The frequency questions included predefined responses up to ' $2+$ times per $d$ ' for foods and ' $6+$ times per d' for beverages. There were also questions on portion sizes (small, medium or large), as compared with the specified medium-size portion. Pictures were used to help with portion size estimations.

Dietary nutrient intake was calculated by multiplying the frequency of consumption of each food by the nutrient content for the specified portion size and then summing over foods. Dietary nutrient intake was adjusted for energy intake using the residuals method ${ }^{(20)}$. To calculate total nutrient intake, the nutrient intake from supplements was added to the energy-adjusted dietary nutrient intake. In a study of the measurement characteristics of the FFQ, deattenuated correlation coefficients comparing $8 \mathrm{~d}$ of dietary intake (four 24-h recalls and $4 \mathrm{~d}$ of diet records) with the FFQ were 0.73 for dietary $\mathrm{Ca}, 0.78$ for total $\mathrm{Ca}, 0.72$ for dietary $\mathrm{Mg}, 0.69$ for total $\mathrm{Mg}$, 0.67 for total $\mathrm{K}$ and 0.67 for total $\mathrm{K}^{(19)}$. The test-retest intraclass correlation coefficient was 0.84 for $\mathrm{Mg}$, and all correlations were $\geq 0.67^{(19)}$.

\section{Covariates}

Covariates were assessed by questionnaires and physical measurement (blood pressure and height and weight used to calculate BMI). As with the dietary assessment, the most recent assessment of covariates prior to $\mathrm{HF}$ hospitalisation was selected for each individual. For co-morbidities, such as myocardial infarction and revascularisation, self-reported conditions existing at the WHI baseline and occurring during the WHI follow-up prior to HF hospitalisation were combined.

\section{Mortality follow-up}

The outcome of interest was all-cause mortality. Follow-up for these analyses started on the date of HF hospitalisation and continued through to the date of death or the last contact with the participant prior to August 2009. Deaths were ascertained by family, friends or health-care providers directly reporting the death to the WHI; family, friends or the US Postal Service responding to mailings; Internet searches (e.g. obituary search engines); the social security death index; or the National Death Index searches ${ }^{(21)}$.

\section{Statistical analysis}

We summarised covariates using means for continuous variables and percentages for categorical variables by mortality status. We calculated Pearson's correlations among $\mathrm{Ca}, \mathrm{Mg}$ and $\mathrm{K}$ intakes. In the subset of women with FFQ completed both before and after HF hospitalisation, we compared intakes from pre- and post-HF questionnaires to assess diet stability.

Cox proportional hazards models were used to estimate the hazard ratios and $95 \% \mathrm{CI}$ of mortality associated with quartiles of the dietary intake of $\mathrm{Ca}, \mathrm{Mg}$ and $\mathrm{K}$ as well as total intake from diet and supplements. Model 1 adjusted for age at HF hospitalisation (linear) and total energy intake (linear). Model 2 further adjusted for race/ethnicity (white, black or other), education (less than high school, high school graduate including some college, college graduate or graduate school), income $(<\$ 20000, \quad \$ 20000-34999, \quad \$ 35000-49999$ or $\geq \$ 50000$ ), married (yes or no), current smoking (yes or no), BMI (linear term), total exercise (metabolic equivalents $\mathrm{h}$ /week, linear term), physical function score (linear term), systolic blood pressure (linear term), diastolic blood pressure (linear term), history of high cholesterol, high blood pressure, diabetes, myocardial infarction, coronary revascularisation and atrial fibrillation, use of off-study post-menopausal hormone therapy, use of diuretics, $\beta$-blockers and angiotensin-converting enzyme inhibitors or angiotensin receptor blockers and WHI study arm. Model 3 additionally adjusted for alcohol intake (none, $0-10 \mathrm{~g} / \mathrm{d}$ or $>10 \mathrm{~g} / \mathrm{d}$ ) and quartiles of $\mathrm{Na}, \mathrm{Ca}$ ( $\mathrm{Mg}$ and $\mathrm{K}$ models), $\mathrm{Mg}$ ( $\mathrm{Ca}$ and $\mathrm{K}$ models), $\mathrm{K}$ ( $\mathrm{Ca}$ and $\mathrm{Mg}$ models), protein, saturated fat, monounsaturated fat, polyunsaturated fat and fibre. Because intake of $\mathrm{Ca}, \mathrm{Mg}$ and $\mathrm{K}$ may reduce blood pressure, adjusting for factors related to blood pressure may be an over-adjustment. We therefore constructed a final model adjusted for all of the factors in model 3, except for systolic and diastolic blood 
pressure, history of high blood pressure and use of diuretics, $\beta$-blockers and angiotensin-converting enzyme inhibitors or angiotensin receptor blockers. Collinearity was examined using the variance inflation factor. None of the variance inflation factors exceeded $4 \cdot 1$, below the threshold of 10 , which has been proposed as an indicator of important collinearity ${ }^{(22)}$. Tests for linear trend were performed by including the median of each quartile as a continuous variable in the models. Potentially non-linear associations were explored using penalised splines ${ }^{(23)}$.
In sensitivity analyses, we excluded participants with self-reported HF at study entry because pre-existing HF may alter diet ( $n$ 303), participants with a history of cancer at baseline or during follow-up because of the cardiotoxic effects of some chemotherapeutic agents ( $n$ 654) and participants in the DM or Ca plus vitamin D trials because these participants may have altered their intake in ways not fully captured by the FFQ ( $n$ 1215). Finally, we excluded participants who did not have a physician diagnosis of $\mathrm{HF}$ at the index hospitalisation, because of the potential for misclassification of disease $(n 251)$.

Table 1. Characteristics of 3340 Women's Health Initiative (WHI) participants with heart failure hospitalisation by mortality

(Mean values and standard deviations or percentages)

\begin{tabular}{|c|c|c|c|c|}
\hline & \multicolumn{2}{|c|}{$\begin{array}{l}\text { Died during follow-up } \\
\qquad(n \text { 1433) }\end{array}$} & \multicolumn{2}{|c|}{$\begin{array}{l}\text { Survived follow-up } \\
\qquad(n \text { 1907) }\end{array}$} \\
\hline & Mean & SD & Mean & SD \\
\hline Age at heart failure hospitalisation (years) & 73.8 & $6 \cdot 7$ & $71 \cdot 9$ & $7 \cdot 2$ \\
\hline \multicolumn{5}{|l|}{ Race/ethnicity (\%) } \\
\hline American Indian/Alaskan native & \multicolumn{2}{|c|}{0.8} & \multicolumn{2}{|c|}{0.3} \\
\hline Asian/Pacific Islander & \multicolumn{2}{|c|}{1.3} & \multicolumn{2}{|c|}{0.6} \\
\hline Black & \multicolumn{2}{|c|}{$10 \cdot 1$} & \multicolumn{2}{|c|}{$10 \cdot 9$} \\
\hline Hispanic & \multicolumn{2}{|c|}{1.4} & \multicolumn{2}{|c|}{$2 \cdot 4$} \\
\hline White not of Hispanic origin & \multicolumn{2}{|c|}{$85 \cdot 6$} & \multicolumn{2}{|c|}{$84 \cdot 8$} \\
\hline Not one of above & \multicolumn{2}{|c|}{0.9} & \multicolumn{2}{|c|}{1.0} \\
\hline \multicolumn{5}{|l|}{ Education (\%) } \\
\hline Less than high school & \multicolumn{2}{|c|}{$9 \cdot 1$} & \multicolumn{2}{|c|}{$8 \cdot 3$} \\
\hline High school graduate/some college & \multicolumn{2}{|c|}{$62 \cdot 3$} & \multicolumn{2}{|c|}{$60 \cdot 4$} \\
\hline College graduate & \multicolumn{2}{|c|}{8.2} & \multicolumn{2}{|c|}{$8 \cdot 3$} \\
\hline Graduate school & & & & \\
\hline Income (\%) & & & & \\
\hline$<\$ 20000$ & & & & \\
\hline$\$ 20000-34999$ & & & & \\
\hline$\$ 35000-49999$ & & & & \\
\hline$\geq \$ 50000$ & & & & \\
\hline Married (\%) & & & & \\
\hline Current cigarette smoking (\%) & & & & \\
\hline $\mathrm{BMI}\left(\mathrm{kg} / \mathrm{m}^{2}\right)$ & 29.9 & $7 \cdot 3$ & 30.9 & 7.4 \\
\hline Physical activity (MET-h/week) & 8.1 & 10.9 & $9 \cdot 4$ & 11.5 \\
\hline Physical function score & 54.2 & $27 \cdot 0$ & $63 \cdot 2$ & $25 \cdot 8$ \\
\hline Systolic blood pressure (mmHg) & 135 & 21 & 134 & 19 \\
\hline Diastolic blood pressure $(\mathrm{mmHg})$ & 71 & 11 & 73 & 11 \\
\hline History of high cholesterol (\%) & & & & \\
\hline History of hypertension (\%) & & & & \\
\hline History of diabetes (\%) & & & & \\
\hline History of myocardial infarction (\%) & & & & \\
\hline History of revascularisation (\%) & & & & \\
\hline History of atrial fibrillation (\%) & & & & \\
\hline Off-study post-menopausal hormone use (\%) & & & & \\
\hline Use of diuretics (\%) & & & & \\
\hline Use of $\beta$-blockers (\%) & & & & \\
\hline Use of ACE inhibitor or ARB (\%) & & & & \\
\hline Total energy $(\mathrm{kJ} / \mathrm{d})$ & 6397 & 2648 & 6565 & 2536 \\
\hline $\mathrm{Ca}(\mathrm{mg} / \mathrm{d})$ & 802 & 346 & 807 & 330 \\
\hline $\mathrm{Mg}(\mathrm{mg} / \mathrm{d})$ & 247 & 54 & 248 & 53 \\
\hline $\mathrm{K}(\mathrm{mg} / \mathrm{d})$ & 2611 & 639 & 2598 & 622 \\
\hline WHI arm (\%) & & & & \\
\hline Oestrogen alone intervention & & & & \\
\hline Oestrogen alone control & & & & \\
\hline Oestrogen plus progestin intervention & & & & \\
\hline Oestrogen plus progestin control & & & & \\
\hline Diet modification intervention & & & & \\
\hline Diet modification control & & & & \\
\hline $\mathrm{Ca} /$ vitamin $\mathrm{D}$ intervention & & & & \\
\hline $\mathrm{Ca} /$ vitamin D control & & & & \\
\hline
\end{tabular}

MET, metabolic equivalents; ACE, angiotensin-converting enzyme inhibitors; ARB, angiotensin receptor blockers. 
We stratified results by whether the participants had a history of IHD prior to the index HF hospitalisation (history of myocardial infarction or revascularisation) and tested whether the associations between the micronutrients and mortality varied by history of IHD by including the product of an indicator variable for IHD and the median values of the micronutrient quartiles.

We tested the proportional hazards assumption by including the product of micronutrients and the natural logarithm of time as a term in the models; there was no evidence of violation of the proportional hazards assumption. Statistical analyses were conducted using SAS version 9.2 and $\mathrm{R}$ version 2.12.1. Two-sided $P$ values $<0.05$ were considered statistically significant.

\section{Results}

Over a median of 4.6 years of follow-up (interquartile range 1.5-6.9 years) after HF hospitalisation, 1433 women died ( $42.9 \%)$. Characteristics of the study population are described in Table 1. The women who died were older, had lower physical activity, were more likely to use diuretics, and were more likely to have diabetes, hypertension, myocardial infarction, coronary revascularisation and atrial fibrillation. Dietary Ca

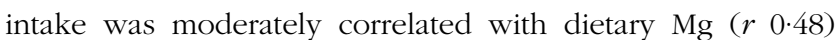
and $\mathrm{K}(r 0.54)$. Dietary intake of $\mathrm{Mg}$ and $\mathrm{K}$ were highly correlated ( $r$ 0.84). Among the 929 women with diet assessment before and after HF hospitalisation, correlations between

Table 2. Calcium, magnesium and potassium from foods and survival among women with heart failure (Hazard ratios (HR) and $95 \%$ confidence intervals)

\begin{tabular}{|c|c|c|c|c|c|}
\hline & Quartile 1 & Quartile 2 & Quartile 3 & Quartile 4 & $P$-trend \\
\hline \multicolumn{6}{|l|}{$\mathrm{Ca}$} \\
\hline Median (mg/d) & 476 & 655 & 833 & 1175 & \\
\hline Deaths & 373 & 346 & 341 & 373 & \\
\hline Person-years & 3589 & 4034 & 3884 & 3778 & \\
\hline Model $1^{*}$ & & & & & 0.29 \\
\hline HR & 1 & 0.82 & 0.82 & 0.89 & \\
\hline $95 \% \mathrm{Cl}$ & Referent & $0.71,0.95$ & $0.71,0.95$ & $0.77,1.03$ & \\
\hline Model $2 \dagger$ & & & & & 0.79 \\
\hline $\mathrm{HR}$ & 1 & 0.88 & 0.90 & 0.95 & \\
\hline $95 \% \mathrm{Cl}$ & Referent & $0.76,1.02$ & $0.78,1.05$ & $0.82,1 \cdot 10$ & \\
\hline Model 3‡ & & & & & 0.63 \\
\hline HR & 1 & 0.86 & 0.88 & 0.92 & \\
\hline $95 \% \mathrm{Cl}$ & Referent & $0.73,1.00$ & $0.75,1.04$ & $0.76,1 \cdot 11$ & \\
\hline \multicolumn{6}{|l|}{$\mathrm{Mg}$} \\
\hline Median (mg/d) & 187 & 227 & 262 & 309 & \\
\hline Deaths & 370 & 343 & 364 & 356 & \\
\hline Person-years & 3721 & 3688 & 3845 & 4030 & \\
\hline Model $1^{*}$ & & & & & 0.002 \\
\hline $\mathrm{HR}$ & 1 & 0.88 & 0.87 & 0.79 & \\
\hline $95 \% \mathrm{Cl}$ & Referent & $0.76,1.01$ & $0.75,1.00$ & $0.68,0.91$ & \\
\hline Model $2 \dagger$ & & & & & 0.09 \\
\hline $\mathrm{HR}$ & 1 & 0.93 & 0.92 & 0.87 & \\
\hline $95 \% \mathrm{Cl}$ & Referent & $0.80,1.08$ & $0.79,1.07$ & $0.75,1.02$ & \\
\hline Model 3‡ & & & & & 0.29 \\
\hline $\mathrm{HR}$ & 1 & 0.86 & 0.88 & 0.84 & \\
\hline \multirow{2}{*}{\multicolumn{6}{|c|}{$0.71,1.04$}} \\
\hline & & & & & \\
\hline Median (mg/d) & 1895 & 2360 & 2754 & 3325 & \\
\hline Deaths & 341 & 373 & 348 & 371 & \\
\hline Person-years & 3754 & 3582 & 3965 & 3982 & \\
\hline Model $1^{*}$ & & & & & 0.03 \\
\hline $\mathrm{HR}$ & 1 & 1.07 & 0.87 & 0.90 & \\
\hline $95 \% \mathrm{Cl}$ & Referent & $0.93,1.24$ & $0.75,1.02$ & $0.78,1.04$ & \\
\hline Model $2 \dagger$ & & & & & 0.57 \\
\hline HR & 1 & $1 \cdot 11$ & 0.95 & 1.00 & \\
\hline $95 \% \mathrm{Cl}$ & Referent & $0.95,1.29$ & $0.81,1.11$ & $0.85,1.17$ & \\
\hline Model 3‡ & & & & & 0.35 \\
\hline HR & 1 & 1.20 & 1.06 & $1 \cdot 16$ & \\
\hline $95 \% \mathrm{Cl}$ & Referent & $1.01,1.43$ & $0.86,1.32$ & $0.90,1.51$ & \\
\hline
\end{tabular}

* Model 1 adjusted for age at heart failure hospitalisation (linear) and total energy intake (linear).

† Model 2 adjusted for variables in model 1 and race/ethnicity (white, black or other), education (less than high school, high school graduate/some college, college graduate or graduate school), income $(<\$ 20000, \$ 20000-34999$, $\$ 35000-49999$ or $\geq \$ 50000$ ), married (yes or no), current smoking (yes or no), BMI (linear term), total exercise (metabolic equivalents h/week, linear term), physical function score (linear term), systolic blood pressure (linear term), diastolic blood pressure (linear term), history of high cholesterol, high blood pressure, diabetes, myocardial infarction, coronary revascularisation and atrial fibrillation, use of off-study post-menopausal hormone therapy, use of diuretics, $\beta$-blockers and angiotensin-converting enzyme inhibitors or angiotensin receptor blockers and Women's Health Initiative study arm.

$\ddagger$ Model 3 adjusted for variables in model 2 and alcohol intake (none, $0-10 \mathrm{~g} / \mathrm{d}$ or $>10 \mathrm{~g} / \mathrm{d}$ ), and quartiles of $\mathrm{Na}$, Ca (Mg and $\mathrm{K}$ models), $\mathrm{Mg}$ ( $\mathrm{Ca}$ and $\mathrm{K}$ models), $\mathrm{K}$ (Ca and Mg models), protein, saturated fat, monounsaturated fat, polyunsaturated fat and fibre. 
pre- and post-HF hospitalisation nutrient intakes were moderate ( $r 0.49$ for $\mathrm{Ca}, 0.56$ for $\mathrm{Mg}$ and 0.54 for $\mathrm{K}$ ).

In age- and energy-adjusted models, dietary intake of $\mathrm{Mg}$ and $\mathrm{K}$ were inversely associated with mortality (Table 2). However, after further multivariable adjustment, there was no significant association between any of the micronutrients and mortality. When dietary $\mathrm{Ca}, \mathrm{Mg}$ and $\mathrm{K}$ were considered as continuous variables using penalised splines, there was no significant linear or nonlinear association. Total intake (from foods and supplements) of $\mathrm{Ca}, \mathrm{Mg}$ and $\mathrm{K}$ was associated with mortality in age- and energy-adjusted models, but the associations were not evident after multivariable adjustment (Table 3 ). The findings were the same when we did not adjust for blood pressure-related variables. Results after excluding participants with baseline selfreported HF, participants with a history of cancer, participants in the DM or Ca plus vitamin D trials or participants who did not have a physician diagnosis of $\mathrm{HF}$ at the index hospitalisation were not materially different. No significant associations of $\mathrm{Ca}$, $\mathrm{Mg}$ or K with mortality were observed among the women with a history of IHD ( $n$ 860) or those without a history of IHD ( $n$ 2480), and tests for interaction between the nutrients and history of IHD were not statistically significant.

Table 3. Calcium, magnesium and potassium from foods and supplements and survival among women with heart failure

(Hazard ratios (HR) and $95 \%$ confidence intervals)

\begin{tabular}{|c|c|c|c|c|c|}
\hline & Quartile 1 & Quartile 2 & Quartile 3 & Quartile 4 & $P$-trend \\
\hline \multicolumn{6}{|l|}{$\mathrm{Ca}$} \\
\hline Median $(\mathrm{mg} / \mathrm{d})$ & 555 & 830 & 1206 & 1844 & \\
\hline Deaths & 357 & 367 & 367 & 342 & \\
\hline Person-years & 3802 & 3649 & 3725 & 4108 & \\
\hline Model $1^{*}$ & & & & & 0.002 \\
\hline $\mathrm{HR}$ & 1 & 1.00 & 0.96 & 0.80 & \\
\hline $95 \% \mathrm{Cl}$ & Referent & $0.86,1.15$ & $0.83,1.11$ & $0.69,0.93$ & \\
\hline Model $2 \dagger$ & & & & & 0.17 \\
\hline $\mathrm{HR}$ & 1 & 1.07 & 1.07 & 0.92 & \\
\hline $95 \% \mathrm{Cl}$ & Referent & $0.92,1.25$ & $0.92,1.24$ & $0.78,1.08$ & \\
\hline Model $3 \ddagger$ & & & & & 0.16 \\
\hline $\mathrm{HR}$ & 1 & 1.08 & 1.07 & 0.91 & \\
\hline $95 \% \mathrm{Cl}$ & Referent & $0.93,1.26$ & $0.91,1.26$ & $0.77,1.09$ & \\
\hline \multicolumn{6}{|l|}{$\mathrm{Mg}$} \\
\hline Median $(\mathrm{mg} / \mathrm{d})$ & 199 & 259 & 320 & 408 & \\
\hline Deaths & 350 & 354 & 373 & 356 & \\
\hline Person-years & 3725 & 3784 & 3748 & 4027 & \\
\hline Model $1^{\star}$ & & & & & 0.03 \\
\hline $\mathrm{HR}$ & 1 & 0.91 & 0.94 & 0.84 & \\
\hline $95 \% \mathrm{Cl}$ & Referent & $0.79,1.06$ & $0.82,1.09$ & $0.72,0.97$ & \\
\hline Model $2 \dagger$ & & & & & 0.98 \\
\hline $\mathrm{HR}$ & 1 & 0.99 & 1.07 & 0.98 & \\
\hline $95 \% \mathrm{Cl}$ & Referent & $0.85,1.15$ & $0.92,1.25$ & $0.84,1.15$ & \\
\hline Model $3 \ddagger$ & & & & & 0.46 \\
\hline HR & 1 & 1.05 & $1 \cdot 12$ & 1.07 & \\
\hline $95 \% \mathrm{Cl}$ & Referent & $0.89,1.24$ & $0.94,1.32$ & $0.88,1.30$ & \\
\hline \multicolumn{6}{|l|}{$\mathrm{K}$} \\
\hline Median (mg/d) & 1907 & 2378 & 2771 & 3346 & \\
\hline Deaths & 342 & 377 & 346 & 368 & \\
\hline Person-years & 3762 & 3566 & 3952 & 4005 & \\
\hline Model $1^{*}$ & & & & & 0.02 \\
\hline $\mathrm{HR}$ & 1 & 1.09 & 0.87 & 0.89 & \\
\hline $95 \% \mathrm{Cl}$ & Referent & $0.95,1.27$ & $0.75,1.01$ & $0.77,1.03$ & \\
\hline Model $2 \dagger$ & & & & & 0.47 \\
\hline HR & 1 & $1 \cdot 14$ & 0.94 & 1.00 & \\
\hline $95 \% \mathrm{Cl}$ & Referent & $0.98,1.32$ & $0.81,1 \cdot 10$ & $0.85,1.17$ & \\
\hline Model 3‡ & & & & & 0.51 \\
\hline HR & 1 & 1.23 & 1.04 & $1 \cdot 14$ & \\
\hline $95 \% \mathrm{Cl}$ & Referent & $1.03,1.46$ & $0.84,1.29$ & $0.88,1.47$ & \\
\hline
\end{tabular}

${ }^{*}$ Model 1 adjusted for age at heart failure hospitalisation (linear) and total energy intake (linear).

† Model 2 adjusted for variables in model 1 and race/ethnicity (white, black or other), education (less than high school, high school graduate/some college, college graduate or graduate school), income $(<\$ 20000, \$ 20000-34999, \$ 35000-49999$ or $\geq \$ 50000)$, married (yes or no), current smoking (yes or no), BMI (linear term), total exercise (metabolic equivalents h/week, linear term), physical function score (linear term), systolic blood pressure (linear term), diastolic blood pressure (linear term), history of high cholesterol, high blood pressure, diabetes, myocardial infarction, coronary revascularisation and atrial fibrillation, use of off-study post-menopausal hormone therapy, use of diuretics, $\beta$-blockers and angiotensin-converting enzyme inhibitors or angiotensin receptor blockers and Women's Health Initiative study arm.

¥ Model 3 adjusted for variables in model 2 and alcohol intake (none, $0-10 \mathrm{~g} / \mathrm{d}$ or $>10 \mathrm{~g} / \mathrm{d}$ ), and quartiles of $\mathrm{Na}, \mathrm{Ca}$ (Mg and $\mathrm{K}$ models), $\mathrm{Mg}$ (Ca and $\mathrm{K}$ models), $\mathrm{K}$ (Ca and $\mathrm{Mg}$ models), protein, saturated fat, monounsaturated fat, polyunsaturated fat and fibre. 


\section{Discussion}

We did not find significant associations between dietary or total intake of $\mathrm{Ca}, \mathrm{Mg}$ and $\mathrm{K}$ and mortality in WHI participants with HF. We had hypothesised that these nutrients would be associated with mortality based on previous research on $\mathrm{HF}$ and other CVD. For example, supplementation with $\mathrm{Ca}, \mathrm{Mg}$ and $\mathrm{K}$ may reduce blood pressure, a risk factor for $\mathrm{HF}^{(11-14)}$. Extremely low $\mathrm{Ca}$ levels can cause HF in rare instances ${ }^{(24)}$. However, $\mathrm{Ca}$ supplements have been associated with increased risk of myocardial infarction and stroke in some studies ${ }^{(16)}$. High dietary intake of $\mathrm{Mg}$ has been inversely associated with the development of hypertension and type 2 diabetes ${ }^{(25,26)}$, risk factors for $\mathrm{HF}$ and with markers of inflammation and endothelial function $^{(9,10)}$. Patients with HF are more likely to have low serum $\mathrm{Mg}$ than other older individuals, and low serum $\mathrm{Mg}$ has been associated with all-cause mortality in HF patients ${ }^{(27,28)}$. Higher $\mathrm{K}$ excretion, which in part reflects greater intake, is associated with a lower rate of $\mathrm{CVD}^{(15)}$. Low serum $\mathrm{K}$ has been associated with mortality in the context of $\mathrm{HF}^{(29,30)}$. In addition, diet patterns and foods with high $\mathrm{Ca}, \mathrm{Mg}$ and $\mathrm{K}$ content have been associated with incident $\mathrm{HF}^{(31-34)}$.

There are a number of potential explanations for the lack of associations observed in the present study. The present hypothesis that intake of $\mathrm{Ca}, \mathrm{Mg}$ and $\mathrm{K}$ are associated with all-cause mortality in women with HF relied on the assumption that availability of these nutrients in the body is related to dietary consumption. HF patients are often aggressively treated with multiple medications, which could confound or mask any influence of diet. Diuretics, which are a mainstay of HF treatment, can directly make an impact on circulating levels of $\mathrm{K}$ and $\mathrm{Mg}$ through urinary excretion ${ }^{(35)}$. We did not have data to examine how dietary intake influences serum levels of $\mathrm{Ca}, \mathrm{Mg}$ and $\mathrm{K}$ in the present population. Prior to HF hospitalisation, $42 \%$ of the population were treated with diuretics. The use of diuretics could weaken the relationship between intake of the micronutrients and the effective exposure to them. In fact, the women who died following hospitalisation for HF were more likely to have hypertension and to use diuretics. We adjusted for diuretic use and other medication use prior to hospitalisation, but we were not able to capture medication use following hospitalisation. Additionally, kidney dysfunction is very common in HF and may influence the retention and availability of $\mathrm{Ca}, \mathrm{Mg}$ and $\mathrm{K}$. We did not have measures of kidney function in the present population.

The present dietary assessment was not ideal. FFQ are known to have substantial errors, which reduces the power to detect modest effects of diet. In addition, we used dietary assessment prior to HF hospitalisation rather than dietary assessment at the time of HF hospitalisation, and the correlations between preand post-HF hospitalisation intake of nutrients were moderate. This could lead to misclassification of diet during the relevant time period, biasing results towards no association if the misclassification is not related to mortality. However, in the present study, the errors in exposure assessment may be related to mortality, and the resulting bias would depend on the relationship between the error and underlying likelihood of death. We were not able to rule out unmeasured or residual confounding, for example, by severity of HF or kidney function, which were not assessed. We did not have information on left ventricular systolic function or adjudicated HF aetiology; the relationship between diet and mortality in patients with HF could plausibly differ by these characteristics. We did examine the relationship between the micronutrients and mortality in women with and without evidence of ischaemic disease prior to HF hospitalisation, and we did not find associations of $\mathrm{Ca}, \mathrm{Mg}$ or $\mathrm{K}$ in women with or without history of IHD. Finally, dietary intake of these nutrients, rather than serum levels, simply may not affect mortality in HF patients. In addition to the limitations of the present study, there were important strengths. These included the racially and ethnically diverse population, the extensive information collected on the WHI participants, the large number of HF hospitalisations among these participants and the relatively long follow-up for post-HF hospitalisation mortality.

In summary, we did not find significant associations between intake of $\mathrm{Ca}, \mathrm{Mg}$ or $\mathrm{K}$ and post-HF hospitalisation mortality in WHI participants. These results do not challenge the present dietary recommendation for HF patients. Further research is needed to conclusively determine whether nutrient intake can reduce mortality in HF patients.

\section{Acknowledgements}

All authors were involved in the design of the study. J. M. S., L. G. S., L. W. M., J. D. C. and C. E. L. collected the data. E. B. L. performed the statistical analysis and wrote the paper. All authors revised the paper and are responsible for the final manuscript. The authors declare no conflict of interest. The WHI program is funded by the National Heart, Lung, and Blood Institute, National Institutes of Health, US Department of Health and Human Services through contracts N01WH 22110, 24152, 32100-2, 32105-6, 32108-9, 32111-13, 32115, 32118-32119, 32122, 42107-26, 42129-32 and 44221. The authors thank the WHI investigators and staff for their dedication, and the study participants for making the program possible.

Program Office: (National Heart, Lung, and Blood Institute, Bethesda, MD) Jacques Rossouw, Shari Ludlam, Dale Burwen, Joan McGowan, Leslie Ford and Nancy Geller. Clinical Coordinating Centre: (Fred Hutchinson Cancer Research Center, Seattle, WA) Garnet Anderson, Ross Prentice, Andrea LaCroix and Charles Kooperberg.

Investigators and Academic Centres: (Brigham and Women's Hospital, Harvard Medical School, Boston, MA) JoAnn E. Manson; (MedStar Health Research Institute/Howard University, Washington, DC) Barbara V. Howard; (Stanford Prevention Research Center, Stanford, CA) Marcia L. Stefanick; (The Ohio State University, Columbus, OH) Rebecca Jackson; (University of Arizona, Tucson/Phoenix, AZ) Cynthia A. Thomson; (University at Buffalo, Buffalo, NY) Jean Wactawski-Wende; (University of Florida, Gainesville/Jacksonville, FL) Marian Limacher; (University of Iowa, Iowa City/Davenport, IA) Robert Wallace; (University of Pittsburgh, Pittsburgh, PA) Lewis Kuller; (Wake Forest University School of Medicine, Winston-Salem, NC) Sally Shumaker. 


\section{References}

1. Ghali JK, Kadakia S, Cooper R, et al. (1988) Precipitating factors leading to decompensation of heart failure. Traits among urban blacks. Arch Intern Med 148, 2013-2016.

2. GISSI-HF Investigators (2008) Effect of $n-3$ polyunsaturated fatty acids in patients with chronic heart failure (the GISSIHF trial): a randomised, double-blind, placebo-controlled trial. Lancet 372, 1223-1230.

3. Morgan DR, Dixon LJ, Hanratty CG, et al. (2006) Effects of dietary omega-3 fatty acid supplementation on endothelium-dependent vasodilation in patients with chronic heart failure. Am J Cardiol 97, 547-551.

4. Evangelista LS, Heber D, Li Z, et al. (2009) Reduced body weight and adiposity with a high-protein diet improves functional status, lipid profiles, glycemic control, and quality of life in patients with heart failure: a feasibility study. J Cardiovasc Nurs 24, 207-215.

5. Aquilani R, Opasich C, Gualco A, et al. (2008) Adequate energy-protein intake is not enough to improve nutritional and metabolic status in muscle-depleted patients with chronic heart failure. Eur J Heart Fail 10, 1127-1135.

6. Witte KK, Nikitin NP, Parker AC, et al. (2005) The effect of micronutrient supplementation on quality-of-life and left ventricular function in elderly patients with chronic heart failure. Eur Heart J 26, 2238-2244.

7. Lennie TA, Chung ML, Habash DL, et al. (2005) Dietary fat intake and proinflammatory cytokine levels in patients with heart failure. J Card Fail 11, 613-618.

8. Weaver CM (2001) Calcium. In Present Knowledge in Nutrition, pp. 273-280 [BA Bowman and RM Russell, editors]. Washington, DC: ILSI Press.

9. Chacko SA, Song Y, Nathan L, et al. (2010) Relations of dietary magnesium intake to biomarkers of inflammation and endothelial dysfunction in an ethnically diverse cohort of postmenopausal women. Diabetes Care 33, 304-310.

10. Song Y, Li TY, van Dam RM, et al. (2007) Magnesium intake and plasma concentrations of markers of systemic inflammation and endothelial dysfunction in women. Am J Clin Nutr 85, 1068-1074.

11. Dickinson HO, Nicolson DJ, Campbell F, et al. (2006) Magnesium supplementation for the management of essential hypertension in adults. The Cochrane Database Systematic Reviews, issue 3, CD004640.

12. Dickinson HO, Nicolson DJ, Cook JV, et al. (2006) Calcium supplementation for the management of primary hypertension in adults. The Cochrane Database Systematic Reviews, CD004639.

13. Dickinson HO, Nicolson DJ, Campbell F, et al. (2006) Potassium supplementation for the management of primary hypertension in adults. The Cochrane Database Systematic Reviews, issue 3, CD004641.

14. Beyer FR, Dickinson HO, Nicolson DJ, et al. (2006) Combined calcium, magnesium and potassium supplementation for the management of primary hypertension in adults. The Cochrane Database Systematic Reviews, issue 3, CD004805.

15. Cook NR, Obarzanek E, Cutler JA, et al. (2009) Joint effects of sodium and potassium intake on subsequent cardiovascular disease: the trials of hypertension prevention follow-up study. Arch Intern Med 169, 32-40.

16. Bolland MJ, Grey A, Avenell A, et al. (2011) Calcium supplements with or without vitamin D and risk of cardiovascular events: reanalysis of the Women's Health Initiative limited access dataset and meta-analysis. BMJ 342, d2040.
17. Hays J, Hunt JR, Hubbell FA, et al. (2003) The Women's Health Initiative recruitment methods and results. Ann Epidemiol 13, S18-S77.

18. Langer RD, White E, Lewis CE, et al. (2003) The Women's Health Initiative Observational Study: baseline characteristics of participants and reliability of baseline measures. Ann Epidemiol 13, S107-S121.

19. Patterson RE, Kristal AR, Tinker LF, et al. (1999) Measurement characteristics of the Women's Health Initiative food frequency questionnaire. Ann Epidemiol 9, 178-187.

20. Willett WC (1998) Nutritional Epidemiology, 2nd ed. New York: Oxford University Press.

21. Women's Health Initiative (2010) WHI Clinical Coordinating Center Women's Health Initiative Scientific Resources. http:// www.whiscience.org/ (accessed 20 January 2010).

22. Kleinbaum DG, Kupper LL, Muller KE, et al. (1998) Applied Regression Analysis and Other Multivariable Methods, 3rd ed. Pacific Grove: Brooks/Cole.

23. Thurston SW, Eisen EA \& Schwartz J (2002) Smoothing in survival models: an application to workers exposed to metalworking fluids. Epidemiology 13, 685-692.

24. Mikhail N, El-Bialy A \& Grosser J (2001) Severe hypocalcemia: a rare cause of reversible heart failure. Congest Heart Fail 7, 256-258.

25. Song Y, Manson JE, Buring JE, et al. (2004) Dietary magnesium intake in relation to plasma insulin levels and risk of type 2 diabetes in women. Diabetes Care 27, 59-65.

26. Song Y, Sesso HD, Manson JE, et al. (2006) Dietary magnesium intake and risk of incident hypertension among middle-aged and older US women in a 10-year follow-up study. Am J Cardiol 98, 1616-1621.

27. Arinzon Z, Peisakh A, Schrire S, et al. (2009) Prevalence of hypomagnesemia (HM) in a geriatric long-term care (LTC) setting. Arch Gerontol Geriatr 51, 36-40.

28. Adamopoulos C, Pitt B, Sui X, et al. (2009) Low serum magnesium and cardiovascular mortality in chronic heart failure: a propensity-matched study. Int J Cardiol 136, 270-277.

29. Ahmed A, Zannad F, Love TE, et al. (2007) A propensity-matched study of the association of low serum potassium levels and mortality in chronic heart failure. Eur Heart J 28, 1334-1343.

30. Bowling CB, Pitt B, Ahmed MI, et al. (2010) Hypokalemia and outcomes in patients with chronic heart failure and chronic kidney disease: findings from propensity-matched studies. Circ Heart Fail 3, 253-260.

31. Levitan EB, Wolk A \& Mittleman MA (2009) Consistency with the DASH diet and incidence of heart failure. Arch Intern Med 169, 851-857.

32. Levitan EB, Wolk A \& Mittleman MA (2009) Relation of consistency with the dietary approaches to stop hypertension diet and incidence of heart failure in men aged 45 to 79 years. Am J Cardiol 104, 1416-1420.

33. Djousse L, Rudich T \& Gaziano JM (2008) Nut consumption and risk of heart failure in the Physicians' Health Study I. $A m$ J Clin Nutr 88, 930-933.

34. Pfister R, Sharp SJ, Luben R, et al. (2011) Plasma vitamin C predicts incident heart failure in men and women in European Prospective Investigation into Cancer and NutritionNorfolk prospective study. Am Heart J 162, 246-253.

35. Hunt SA, Abraham WT, Chin MH, et al. (2009) 2009 Focused Update Incorporated Into the ACC/AHA 2005 Guidelines for the Diagnosis and Management of Heart Failure in Adults: A Report of the American College of Cardiology Foundation/ American Heart Association Task Force on Practice Guidelines: Developed in Collaboration With the International Society for Heart and Lung Transplantation. Circulation 119, e391-e479. 